\title{
Musculoskeletal disorders among bank office workers in Kuwait
}

Q.A.S. Akrouf, J.O. Crawford, ${ }^{2}$ A.S. Al-Shatti ${ }^{1}$ and M.I. Kamel ${ }^{3}$

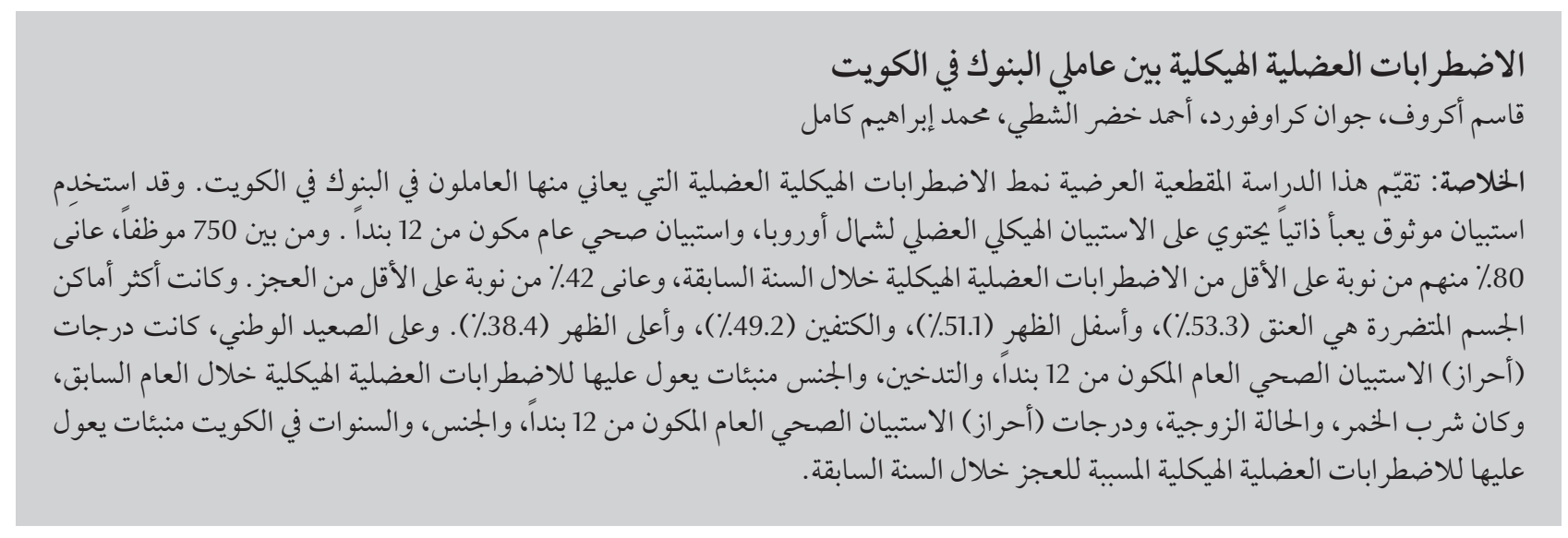

ABSTRACT This cross-sectional observational study assessed the pattern of musculoskeletal disorders (MSDs) suffered by bank office workers in Kuwait. A self-administered validated questionnaire was used that included the Nordic musculoskeletal questionnaire and 12-item general health questionnaire (GHQ12). Of 750 employees, $80 \%$ suffered at least 1 episode of MSD during the previous year and $42 \%$ suffered at least 1 disabling episode. The most affected body parts were the neck (53.5\%), lower back (51.1\%), shoulders (49.2\%) and upper back (38.4\%). Nationality, GHQ12 score, smoking and sex were significant predictors of MSDs during the previous year, while alcohol drinking, marital status, GHQ12 score, years in Kuwait and sex were significant predictors of disabling MSDs during the previous year.

\section{Troubles musculosquelettiques chez des employés de banque au Koweït}

RÉSUMÉ Cette étude transversale d'observation a évalué les caractéristiques des troubles musculosquelettiques (TMS) chez des employés de banque au Koweït. Nous avons utilisé un autoquestionnaire validé comprenant le questionnaire «nordique »sur les TMS et le questionnaire GHQ12 (questionnaire général de santé en 12 questions). Sur 750 employés, 80 \% d'entre eux avaient connu au moins un épisode de TMS au cours de l'année précédente et $42 \%$, au moins un épisode invalidant. Les parties du corps les plus touchées étaient le cou (53,5\%), le bas du dos (51,1\%), les épaules $(49,2 \%)$ et le haut du dos (38,4\%). La nationalité, le score au GHQ12, le tabagisme et le sexe étaient des facteurs prédictifs significatifs de TMS au cours de l'année précédente, alors que la consommation d'alcool, l'état matrimonial, le score au GHQ12, les années passées au Koweït et le sexe étaient des facteurs prédictifs significatifs de TMS invalidants au cours de l'année précédente.

'Department of Occupational Health, Ministry of Health, Kuwait

${ }^{2}$ Department of Occupational Health, University of Birmingham, Birmingham, United Kingdom.

${ }^{3}$ Department of Occupational Health, University of Alexandria, Alexandria, Egypt (Correspondence to M.I. Kamel: kamelafm@yahoo.com). Received: 20/06/07; accepted: 13/09/07 


\section{Introduction}

Rapid technological developments, especially in the use of electronic data, have affected both workers and the workplace. Electronic data are mainly displayed on visual display terminals. Improper body posture and long hours in front of these terminals can result in many health hazards, including eye strain and fatigue and musculoskeletal disorders (MSDs) [1]. It has been stated that MSDs are the most common occupational health problem [2]. Around 1.1 million people in the United Kingdom suffered from MSDs caused by or made worse by work in 2001-02 [2] and MSDs accounted for 11.6 million working days lost during 2006 [3]. In the United States, MSDs constituted $41.4 \%$ of all adult disabilities (41.2 million) during 1990 [4].

Work-related MSDs can affect shoulders, arms, elbows, wrists, hands, back, legs and feet. They are caused by forceful or repetitive movements or a poor working posture. Symptoms include tenderness, aches and pains, tingling, stiffness and swelling. Lower and upper back pain and muscle spasm could be due to incorrect seating, which also affects the cervical spine and neck muscles leading to pain $[5,6]$. Crawford et al. concluded that physical and psychosocial risk factors are implicated in the etiology of MSDs especially those affecting the neck and shoulder regions [7]. Jensen et al. showed that neck symptoms were the most common (53\%) among female call-centre workers, followed by shoulder (42\%) and hand/wrist (30\%) symptoms [1].

Although many studies have dealt with MSDs among office workers in other countries, the exact nature and prevalence of this important health problem has not been studied before in Kuwait. This study was formulated to fill the gap of knowledge in this area. The aims of the study were to assess the pattern of MSDs among bank office workers and to identify the impact of demographic, occupational, psychological and social factors on MSDs.

\section{Methods}

This study was carried out during 2006 in the 36 branches of one banking company in Kuwait, randomly selected from among the major banks in the country. An observational cross-sectional study design was adopted. All bank workers $(n=800)$ using visual display units were recruited for the study. A self-administered questionnaire was distributed personally to each employee.

\section{Tools}

A specially designed self-administered questionnaire included the following: sociodemographic characteristics (age, sex, nationality, marital status, level of education, years in Kuwait and smoking history) and occupational history (type of job and duration in that job). The modified 12-item Goldberg general health questionnaire (GHQ12) was used [8]. This questionnaire assesses psychiatric morbidity or the "inability to carry out one's normal 'healthy' functions and the appearance of new phenomena of a distressing nature". Each question is scored from 0 (better than normal) to 3 (much less than normal). The short version of the standardized Nordic musculoskeletal questionnaire was used to evaluate MSDs [6]. This questionnaire deals with the occurrence of MSDs during the previous 7 days and 12 months as well as their severity. It also deals with the distribution of these disorders by body organ. An Arabic translation of the questionnaire was prepared. Back translation was used to ensure correct translation. The questionnaire was assessed by a jury of 6 occupational and psychiatrist consultants to ensure its validity.
A pilot study was carried out on 15 workers to assess the suitability of the questions in Kuwaiti culture and to reveal any defects in the administrative plan for data collection. Reliability of the questionnaire was studied through repeating the same questionnaire on the 15 workers included in the pilot study. The Cronbach reliability coefficient was more than 0.87 for the questionnaire.

Approval to carry out the study was obtained from the headquarters of the bank. Oral consent was also obtained from workers before filling the questionnaire. All collected data were handled confidentially.

\section{Data analysis}

The pre-coded questionnaire facilitated data entry. The Microsoft Excel program was used for data entry and Epi-Info for statistical analysis of the data. The quality of data was assured by meeting with the workers and their supervisors to explain the purpose of the studyand the nature of the questionnaire, and by checking the completeness of data in the field. After data entry, both manual and electronic (frequency analysis and cross-tabulation) revisions were performed to verify data entry.

The prevalence of MSDs during the previous 12 months or attacks occurring during 7 days were calculated if any part of the body was affected. Also the mean GHQ12 score and the number of body parts affected by MSDs were calculated.

Statistical analysis of the results included both descriptive and analytic techniques. Statistical tests used for analysis of the results included the chi-squared and Fisher exact test for qualitative data and Mann-Whitney and Spearman coefficients for nonparametric data. Odds ratio (OR) and multiple logistic techniques were used to determine risk factors. The level of significance adopted for this study was $P \leq 0.05$. 


\begin{tabular}{|c|c|c|}
\hline Characteristic & No. & $\%$ \\
\hline \multicolumn{3}{|l|}{ Sex } \\
\hline Male & 356 & 47.5 \\
\hline Female & 394 & 52.5 \\
\hline Mean (SD) age (years) & \multicolumn{2}{|c|}{$33.2(9.1)$} \\
\hline \multicolumn{3}{|l|}{ Nationality } \\
\hline Kuwaiti & 404 & 53.9 \\
\hline Non-Kuwaiti & 346 & 46.1 \\
\hline \multicolumn{3}{|l|}{ Marital status } \\
\hline Married & 472 & 62.9 \\
\hline Single & 278 & 37.1 \\
\hline \multicolumn{3}{|l|}{ Education level } \\
\hline Secondary or less & 67 & 8.9 \\
\hline Post-secondary institute & 256 & 34.2 \\
\hline University & 387 & 51.6 \\
\hline Higher university & 40 & 5.3 \\
\hline Mean (SD) time in Kuwait (years) & \multicolumn{2}{|c|}{$19.1(11.8)$} \\
\hline \multicolumn{3}{|l|}{ Smoker } \\
\hline Yes & 193 & 25.7 \\
\hline No & 557 & 74.3 \\
\hline \multicolumn{3}{|l|}{ Alcohol drinker } \\
\hline Yes & 73 & 9.7 \\
\hline No & 677 & 90.3 \\
\hline \multicolumn{3}{|l|}{$J o b$} \\
\hline Clerical & 43 & 5.7 \\
\hline Public relations & 69 & 9.2 \\
\hline Customer services & 377 & 50.3 \\
\hline Supervisor & 18 & 2.4 \\
\hline Assistant manager & 46 & 6.1 \\
\hline Manager & 95 & 12.7 \\
\hline Other & 102 & 13.6 \\
\hline Mean (SD) job duration (years) & \multicolumn{2}{|c|}{$7.6(7.5)$} \\
\hline \multicolumn{3}{|l|}{ GHQ12 score } \\
\hline Normal (0-12) & 472 & 62.9 \\
\hline Mild distress (13-24) & 263 & 35.1 \\
\hline Moderate to severe distress (25-36) & 15 & 2.0 \\
\hline Mean (SD) score & \multicolumn{2}{|c|}{$11.5(5.4)$} \\
\hline
\end{tabular}

$S D=$ standard deviation $; G H Q 12=12$-item general health questionnaire .

\section{Results}

The questionnaire was completed and returned by 750 of the 800 bank workers, giving a response rate of $93.8 \%$. Their mean age was 33.2 (SD 9.1) years ( $\mathrm{Ta}$ ble 1) and over half the respondents were females (52.5\%). The predominant nationality was Kuwaiti (53.9\%). Almost all the respondents (90.2\%) had higher than secondary education. A majority were married (62.9\%). Only one-quarter were smokers $(25.7 \%)$, while alcohol drinkers were only $9.7 \%$. The mean duration in their job was 7.6 (SD 7.5) years. The mean score on the GHQ12 was "upper normal" [11.5 (SD 5.4)] and only a minority $(2.0 \%)$ were rated as having moderate to severe psychological distress (score 25-36).

Of all bank workers, 57\% reported suffering from MSDs during the previous week, while $80 \%$ suffered such disorders during the previous year. A total of $42 \%$ of the bank workers had suffered disabling attacks of MSDs in the previous year. Table 2 shows that lower back (30.3\%), shoulders (29.5\%) and neck (28.0\%) were the most affected body parts during the previous week. Elbow (5.1\%), hips $(7.5 \%)$ and ankles/feet $(9.5 \%)$ were the least affected. For MSDs occurring during the previous year, the affected body parts showed a slightly different priority, as neck (53.5\%), lower back (51.1\%) and shoulders (49.2\%) topped the list, and elbows (11.5\%), hips (13.3\%) and ankles/feet (16.8\%) respectively had the lowest prevalence. The most disabling MSDs affecting bank workers were in the wrists/hands (28.3\%) and lower $\operatorname{back}(24.5 \%)$.

Table 3 portrays the univariate analysis of factors associated with MSDs among bank workers. Factors positively associated with the occurrence of MSDs during the previous week were: being female, having Kuwaiti nationality and scoring high on the GHQ12; while factors positively associated with the occurrence of MSDs during the previous year were: being female, having Kuwaiti nationality, being younger, holding more than a secondary education certificate and having a high GHQ12 score. Factors associated with disabling MSDs were: being female, drinking alcohol, being married, longer job duration and a higher GHQ12.

Table 4 shows the significant predictors of MSDs using multiple logistic regression models. Female sex and high GHQ12 score were significantly associated with all forms of MSDs, while Kuwaiti nationality was significantly associated with attacks, whether occurring during the previous week or year. Older age, longer job duration, drinking alcohol and being married were 


\begin{tabular}{|c|c|c|c|c|c|c|}
\hline \multirow[t]{2}{*}{ Body part affected by MSD } & \multicolumn{2}{|c|}{ Previous 7 days } & \multicolumn{2}{|c|}{ Previous 12 months } & \multicolumn{2}{|c|}{ Disabling attack } \\
\hline & No. & $\%$ & No. & $\%$ & No. & $\%$ \\
\hline \multicolumn{7}{|l|}{ Neck } \\
\hline No & 540 & 72.0 & 349 & 46.5 & 642 & 85.6 \\
\hline Yes & 210 & 28.0 & 401 & 53.5 & 108 & 14.4 \\
\hline \multicolumn{7}{|l|}{ Shoulder } \\
\hline No & 529 & 70.5 & 381 & 50.8 & 622 & 82.9 \\
\hline Yes & 221 & 29.5 & 369 & 49.2 & 128 & 17.1 \\
\hline Right & 82 & 10.9 & 139 & 18.5 & - & - \\
\hline Left & 34 & 4.5 & 57 & 7.6 & - & - \\
\hline Both & 105 & 14.0 & 173 & 23.1 & - & - \\
\hline \multicolumn{7}{|l|}{ Elbow } \\
\hline No & 712 & 94.9 & 664 & 88.5 & 727 & 96.9 \\
\hline Yes & 38 & 5.1 & 86 & 11.5 & 23 & 3.1 \\
\hline Right & 14 & 1.9 & 33 & 4.4 & - & - \\
\hline Left & 11 & 1.5 & 18 & 2.4 & - & - \\
\hline Both & 13 & 1.7 & 35 & 4.7 & - & - \\
\hline \multicolumn{7}{|l|}{ Hand/wrist } \\
\hline No & 641 & 85.5 & 538 & 71.7 & 538 & 71.7 \\
\hline Yes & 109 & 14.5 & 212 & 28.3 & 212 & 28.3 \\
\hline Right & 69 & 9.2 & 140 & 18.7 & - & - \\
\hline Left & 16 & 2.1 & 30 & 4.0 & - & - \\
\hline Both & 24 & 3.2 & 42 & 5.6 & - & - \\
\hline \multicolumn{7}{|l|}{ Upper back } \\
\hline No & 580 & 77.3 & 462 & 61.6 & 640 & 85.3 \\
\hline Yes & 170 & 22.7 & 288 & 38.4 & 110 & 14.7 \\
\hline \multicolumn{7}{|l|}{ Lower back } \\
\hline No & 523 & 69.7 & 367 & 48.9 & 566 & 75.5 \\
\hline Yes & 227 & 30.3 & 383 & 51.1 & 184 & 24.5 \\
\hline \multicolumn{7}{|l|}{ Hips } \\
\hline No & 694 & 92.5 & 650 & 86.7 & 716 & 95.5 \\
\hline Yes & 56 & 7.5 & 100 & 13.3 & 34 & 4.5 \\
\hline \multicolumn{7}{|l|}{ Knees } \\
\hline No & 649 & 86.5 & 578 & 77.1 & 674 & 89.9 \\
\hline Yes & 101 & 13.5 & 172 & 22.9 & 76 & 10.1 \\
\hline \multicolumn{7}{|l|}{ Foot/ankle } \\
\hline No & 680 & 90.7 & 624 & 83.2 & 700 & 93.3 \\
\hline Yes & 70 & 9.3 & 126 & 16.8 & 50 & 6.7 \\
\hline
\end{tabular}

additional risk predictors for disabling MSDs among these bank workers.

\section{Discussion}

The increased use of computer screens, keyboards and mouses in recent years has been associated with an increased prevalence of disorders in the neck and upper extremities [9]. Poor workstation design, continuous computer use for the entire workday and repetitive computer work, such as data entry, have been associated with an increased risk of developing symptoms related to musculoskeletal disorders [10,11].

Musculoskeletal disorders are highly prevalent and potentially disabling conditions that undermine the available health resources [4] and impose heavy costs on employers and society $[2,3,12,13]$. In industrialized societies, 


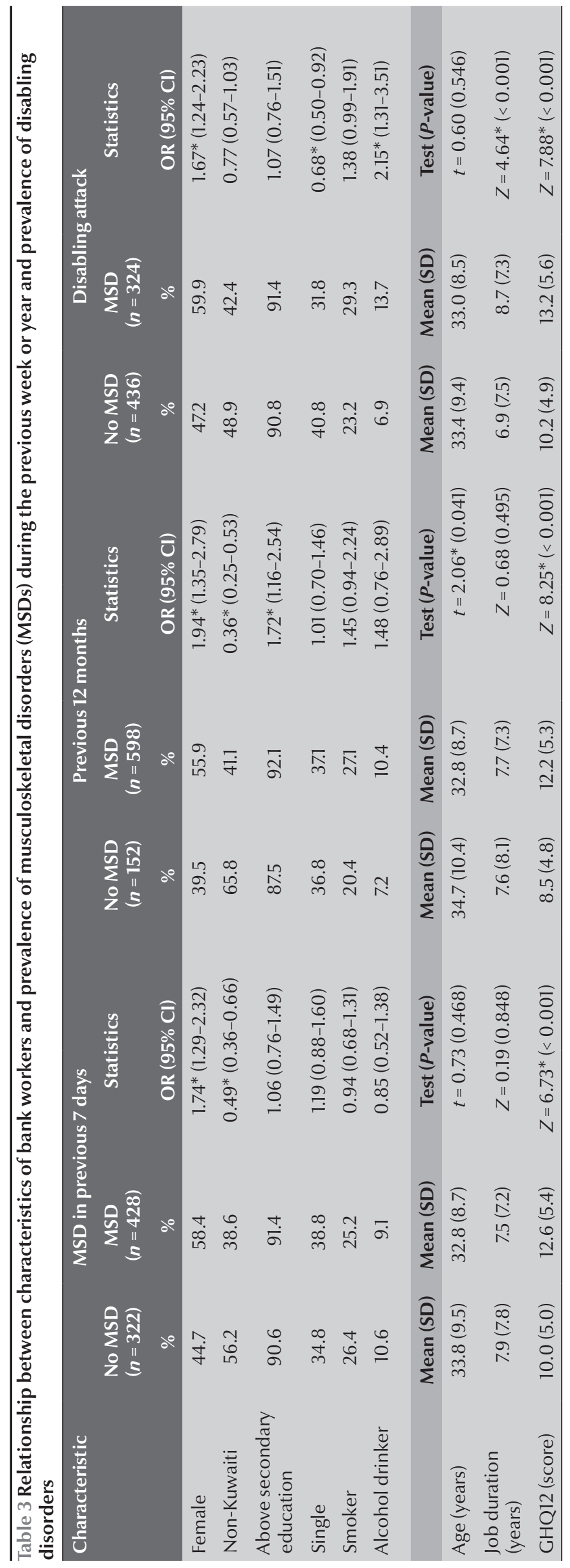

MSDs are one of the most common causes of temporary work disability and the main cause of permanent work disability, accounting for high productivity losses $[14,15]$.

The current study was formulated to assess the prevalence of MSDs among bank workers and reveal the impact of personal and psychological factors on such disorders. To achieve such aims an observational cross-sectional study was carried out in branches of one of the major banks in Kuwait. The study comprised 800 bank workers with a response rate of $93.5 \%$. The short version of the Nordic questionnaire was used to analyse MSDs and a modified GHQ12 self-administered questionnaire was used for assessment of psychiatric disorders. The large number of studied workers and high response rate can be considered as a good representation of bank workers. However, the differences in the design of workstations in the studied branches of the bank could form one source of bias. Although in cross-sectional design only survivors are studied, the mild nature of MSDs rarely leads to high rates of turnover among bank workers.

Ourstudy showed that $80 \%$ of workers suffered from at least 1 attack of a MSD in the previous year, while $57 \%$ suffered from attacks during the previous week. Disabling MSDs were suffered by $42 \%$. Using the same questionnaire Woods reported the following corresponding proportions: $86 \%, 56 \%$ and $30 \%$ respectively [ 16$]$. The 2 studies agree with regard to ranking of commonly affected organs. Our study revealed that neck (53.5\%), lower back (51.1\%) and shoulders (41.6\%) were the most commonly affected body parts during the previous year. Similar results were also found for MSDs occurring in the previous week. Several studies have shown an increased risk of neck disorders among office workers [17-19]. There is strong evidence supporting static or maintained postures as a risk factor for MSDs of the neck and shoulders [20] and a positive relationship has been identified with the 


\begin{tabular}{|c|c|c|c|c|c|c|}
\hline \multirow[t]{2}{*}{ Factor } & \multicolumn{2}{|c|}{ Previous 7 days } & \multicolumn{2}{|c|}{ Previous 12 months } & \multicolumn{2}{|c|}{ Disabling attack } \\
\hline & $\beta$ & OR $(95 \% \mathrm{Cl})$ & $\beta$ & OR $(95 \% \mathrm{Cl})$ & $\beta$ & OR $(95 \% \mathrm{Cl})$ \\
\hline Age & - & - & - & - & -0.062 & $0.94(0.91-0.97)$ \\
\hline Sex & 0.335 & $1.40(1.03-1.90)$ & 0.477 & $1.63(1.09-2.45)$ & 0.409 & 1.51 (1.09-2.09) \\
\hline Nationality & -0.593 & $0.55(0.41-0.75)$ & -0.919 & $0.40(0.27-0.59)$ & - & - \\
\hline Marital status & - & - & - & - & -0.523 & $0.59(0.41-0.85)$ \\
\hline Job duration & - & - & - & - & 0.079 & $1.08(1.05-1.21)$ \\
\hline Smoker & - & - & 0.639 & $1.90(1.18-3.06)$ & - & - \\
\hline Alcohol drinker & - & - & - & - & 0.877 & $2.40(1.42-4.06)$ \\
\hline GHQ12 score & 0.09 & 1.09 (1.06-1.13) & 0.153 & $1.16(1.11-1.22)$ & 0.101 & $1.11(1.07-1.14)$ \\
\hline Constant & -0.359 & - & 0.377 & - & -0.617 & - \\
\hline
\end{tabular}

Age, job duration and GHQ12 scales were quantitative variables; sex was coded: male =1, female = 2; nationality: Kuwaiti $=1$, Non-Kuwaiti = 2; marital status: married = 0 , currently single $=7$; smoker and alcohol drinker: yes $=1$, no $=0$.

$O R=$ odds ratio; $C I=$ confidence interval; $G H Q 12=12$-item general health questionnaire .

duration of fixed sedentary posture at work [21]. Also limited breaks are a significant risk factor for neck disorders $[22,23]$.

The current study showed that women were more likely to suffer from MSDs than men, either during the previous year ( $84.8 \%$ compared with $74.2 \%$ ) or the previous week (63.5\% compared with 50\%). Furthermore they also tended to suffer more disabling attacks (47.7\% compared with $35.4 \%$ ). Many studies revealed a gender difference with more women being affected $[7,24,25]$. These gender differences could be attributed to differences in workloads or biological and anthropometric measurements [25].

Gender differences in addition to psychological status proved to be significant predictors of all forms of MSDs detected by this study. Psychosocial status was found to be consistently related to MSDs by other workers $[3,7,26]$.

Smoking was also shown to be a significant predictor for MSDs occurring during the previous 12 months, while drinking alcohol, duration at work and age could predict disabling attacks of MSDs.
The high prevalence of MSDs may be a symptom of "system failure" that should be addressed to improve both quality and productivity. Programmes for prevention of MSDs should be incorporated within a widener ergonomic approach to promote the health of workers. Also, a comprehensive approach including system goals, task allocation, work organization and job design is needed. Further studies are required to elaborate the relation between job demands and loads as well as other organizational and social factors on occurrence of MSDs

\section{References}

1. Jensen $C$ et al. Musculoskeletal symptoms and duration of computer and mouse use. International journal of industrial ergonomics, 2002, 30(4-5):265-75.

2. New guidance on using computers and preventing RSI. HSE press release E030:03. Caerphilly, United Kingdom, Health and Safety Executive, 2003 (http://hse.gov.uk/press/2003/e03030. htm, accessed 26 May 2009).

3. Musculoskeletal disorders. United Kingdom Health and Safety Executive [website] (http://www.hse.gov.uk/msd/index.htm, accessed 27 April 2009).

4. Prevalence of disabilities and associated health conditions among adults-United States, 1999. Morbidity and mortality weekly report, 2001, 50(7):120-5.

5. Printing-a pain in the neck. HSE press release E038:04. Caerphilly, United Kingdom, Health and Safety Executive, 2004 (http://hse.gov.uk/press/2004/e04038.htm, accessed 27 April 2009).
6. Kuorinka I et al. Standardized Nordic questionnaires for the analysis of musculoskeletal symptoms. Applied ergonomics, 1987, 18(3):233-7.

7. Crawford JO et al. The prevention of musculoskeletal disorders within the telecommunications sectors: a systemic review of scientific literature. Birmingham, Institute of Occupational and Environmental Medicine Division of Primary Care, and School of Medicine, University of Birmingham, 2005 (http://hesa. etui-rehs.org/uk/dossiers/files/The Prevention_of_MuSculoskeletal_Disorders.pdf, accessed 27 April 2009).

8. Goldberg D. Manual of the general health questionnaire. Windsor, United Kingdom, National Foundation for Educational Research, 1978.

9. Cook C, Burgess-Limerrick R, Chang SW. The prevalence of neck and upper extremity musculoskeletal symptoms in computer mouse users. International journal of industrial ergonomics, 2000, 26(3):347-56. 
10. Sillanpaa J et al. Effect of work with visual display units on musculoskeletal disorders in the office environment. Occupational medicine, 2003, 53(7):443-51.

11. Social Security Administration Teleservice Centres, Boston, Massachusetts, Fort Lauderdale, Florida. HHE ReportNo. HETA-92-0382 2450. Atlanta, Georgia, National Institute for Occupational Safety and Health, 1992.

12. Manual handling assessment charts. Leaflet INDG383. Caerphilly, United Kingdom, Health and Safety Executive, 2003 (www. hse.gov.uk/pubns/indg383.pdf, accessed 26 May 2009).

13. Buckle P. Ergonomics and musculoskeletal disorders: overview. Occupational medicine, 2005, 55:164-7.

14. Abasolo L et al. A health system programme to reduce work disability related to musculoskeletal disorders. Annals of internal medicine, 2005, 143(6):404-14.

15. Haldeman S. Failure of pathology model to predict back pain. Spine, 1991, 15:718-24.

16. Woods V. Musculoskeletal disorders and visual strain in intensive data processing workers. Occupational medicine, 2005 , 55(2):21-7.

17. Leclerc A et al. One-year predictive factors for various aspects of neck disorders. Spine, 1999, 24:1455-62.

18. Pietri-Taleb F et al. Longitudinal study on the role of personality characteristics and psychological distress in neck trouble among working men. Pain, 1994, 58:261-7.

19. Leino P, Magni G. Depressive and distress symptoms as predictors of low back pain, neck-shoulder pain, and other mus- culoskeletal morbidity: a 10-year follow-up of metal industry employees. Pain, 1993, 53:89-94.

20. Display screen equipment (DSE)-health problems. Mainstream research news. Issue 6, October 1998. United Kingdom Health and Safety Executive [website] (http:www.hse.gov.uk/ research/journals/mrn698b.htm, accessed 27 April 2009).

21. Winkei J, Westgaard R. Occupational and individual risk factors for shoulder-neck complaints. International journal of industrial ergonomics, 1992, 10:1-20.

22. Devereux JJ, Vlachonikolis IG, Buckle PW. Epidemiological study to investigate potential interaction between physical and psychosocial factors at work that may increase the risk of symptoms of musculoskeletal disorder of the neck and upper limb. Occupational and environmental medicine, 2002, 59(4):269-77.

23. Bergqvist $\mathrm{U}$ et al. The influence of VDU work on musculoskeletal disorders. Ergonomics, 1995, 38(4):754-62.

24. Korhonen $\mathrm{T}$ et al. Work related and individual predictors for incident neck pain among office employees working with video display units. Occupational and environmental medicine, 2003, 60(7):475-82.

25. Jensen $\mathrm{C}$ et al. Work-related psychosocial, physical and individual factors associated with musculoskeletal symptoms in computer users. Work and stress, 2002, 16(2):107-20.

26. Baker NA, Jacobs K, Carifio J. The ability of background factors, work practices, and psychosocial variables to predict the severity of musculoskeletal discomfort. Occupational ergonomics, 2000, 2(1):27-41.

\section{Note from the Editor}

We wish to draw the kind attention of our potential authors to the importance of applying the editorial requirements of EMHJ when preparing their manuscripts for submission for publication. These provisions can be seen in the Guidelines for Authors, which are available online at http:/ / www.emro.who.int/emhj.htm, and are published at the end of the first issue of each volume. We regret that we are unable to consider papers that do not conform to the Guidelines. 